\title{
Population dynamics of the invasive fish, Gambusia affinis, in irrigation impoundments in the Sundays River Valley, Eastern Cape, South Africa
}

\author{
Dylan H Howell', Darragh J Woodford ${ }^{2,3 *}$, Olaf LF Weyl ${ }^{2,3}$ and William Froneman ${ }^{1}$ \\ 'Department of Zoology and Entomology, Rhodes University, Grahamstown, South Africa \\ ${ }^{2}$ South African Institute for Aquatic Biodiversity, Grahamstown, South Africa \\ ${ }^{3}$ Centre for Invasion Biology, South African Institute for Aquatic Biodiversity, Grahamstown, South Africa
}

\begin{abstract}
The alien invasive Gambusia affinis is one of the most widely introduced fish species on the planet, and has established in freshwater ecosystems across South Africa. The invasion ecology and, in particular, the population dynamics of the species in this country are, however, poorly understood. In this study the relative abundance and population dynamics of G. affinis were quantified in 5 interconnected irrigation impoundments within the Sundays River Valley, Eastern Cape. Four fish surveys were conducted from early summer (February 2012) to early winter (June 2012). Repeated-measures ANOVA analyses on the catch per unit effort (CPUE) of G. affinis between sampling events and dams revealed significant differences in population dynamics among dams, although an overall trend of rapid increase followed by plateau in summer, with a rapid decline in winter was seen in most dams. A general linear model assessing the role of biotic and abiotic factors on G. affinis CPUE found that water temperature and the presence of the native fish Glossogobius callidus had significant effects on the CPUE of G. affinis. While winter drops in temperature are likely to have caused mortality in G. affinis populations, and may act as the primary regulator of G. affinis establishment success in South African impoundments, the negative effect of G. callidus densities on G. affinis suggests competitive or predator-prey interactions with the native species.

Keywords: Mosquitofish, population growth rate, invasive success, establishment
\end{abstract}

\section{INTRODUCTION}

Species invasions are a principle driver of biodiversity losses (Lowe et al., 2000), and identification of what determines successful invasions is a prerequisite for adopting sound conservation policies (Leprieur et al., 2008). Freshwater ecosystems are at the forefront of the global biodiversity crisis, with more species facing local extinction than in marine and terrestrial environments (Johnson et al., 2008). Hydrological alterations and biological invasions represent two of the greatest threats to freshwater biota (Johnson et al., 2008). Invasive fishes in particular have had dramatic impacts on the native biota in aquatic ecosystems and are largely responsible for habitat degradation and species loss (Mack et al., 2000).

South Africa is an alien invasive fish hotspot (Van Rensburg et al., 2011). Sixteen of the thirty IUCN red-listed fish species native to South Africa are threatened primarily by predatory non-native fish species (Richardson et al., 2010). As a result, a number of native fishes, amphibians and invertebrates have become locally extinct (Van Rensburg et al., 2011). In addition to their direct impacts on native species, invasive fish also negatively affect aquatic macro-invertebrates and can alter habitats (Richardson et al., 2010).

\footnotetext{
To whom all correspondence should be addressed.

Current affiliation: South African Institute for Aquatic

Biodiversity, Private Bag 1015, Grahamstown 6140, South Africa

푱 +27 46 603-5800; fax: +27 46 622-2403;

e-mail: d.woodford@saiab.ac.za

Received 13 December 2012; accepted in revised form 8 July 2013.
}

The mosquitofish, Gambusia affinis, is listed as one of the world's worst invasive species (Lowe et al., 2000) and, together with the closely-related $G$. holbrooki, is the most widely distributed freshwater fish in the world (Pyke, 2005). Since its introduction into South Africa in 1936 for mosquito control, G. affinis has spread across southern Africa (De Moor and Bruton, 1988). The main vector responsible for the expansion of invasive fish is human-mediated relocation (Van Rensburg et al., 2011), although they are also spread through interconnected waterways (Rauchenberger, 1989). Currently, G. affinis is present in more than $50 \%$ of South Africa's river systems and will continue to colonise new waters where the environmental conditions permit (Van Rensburg et al. 2011).

Although G. affinis is a relatively well-studied fish, its invasive characteristics and impacts on biodiversity are controversial, with research supporting conflicting perceptions that the species is either relatively benign or a significant threat to native species (Pyke, 2008). While humans have regarded G. affinis as beneficial because of their control of mosquitoes, G. affinis is considered likely to have deleterious impacts on the native fish, frogs and aquatic invertebrates with which they interact (Pyke and White, 2000). Few quantitative studies, however, exist that describe the population dynamics of G. affinis in systems where it is introduced, or the direct impacts they have on native species in these habitats (Pyke, 2008). For example, reduced densities of G. affinis are often recorded during winter months relative to summer, although the reasons for this pattern are still not well understood (Pyke, 2005). The lack of information on this species is particularly acute in South Africa, where most existing studies on G. affinis biology are unpublished (De Moor and Bruton, 1988). 


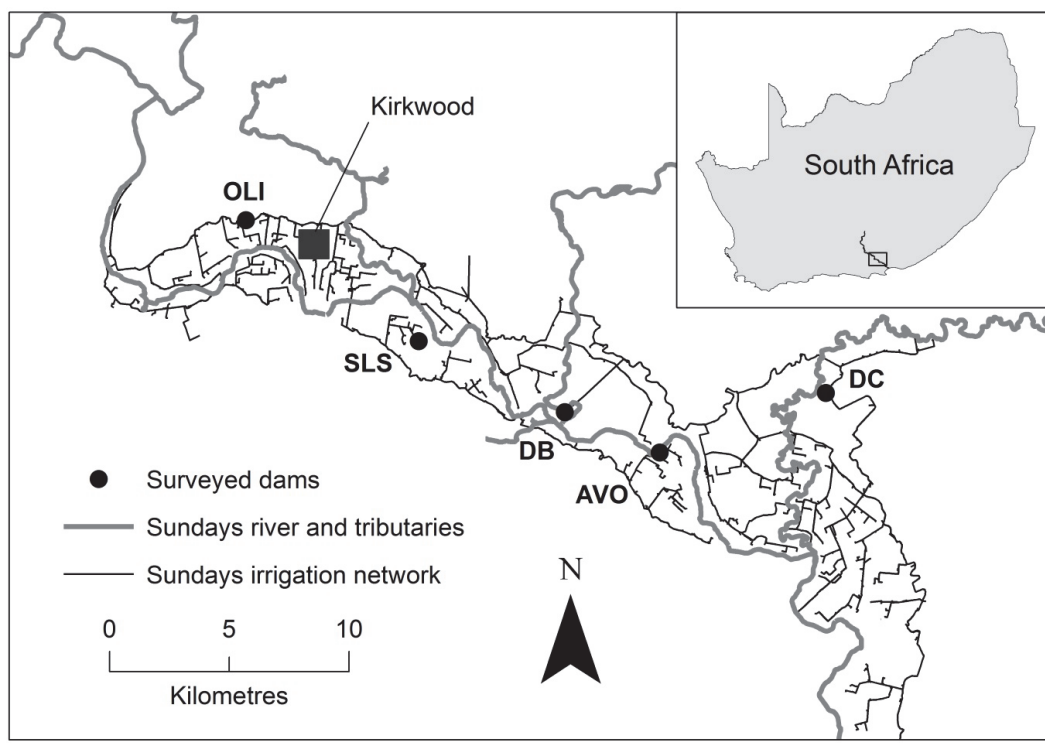

Figure 1

The Sundays River Valley illustrated with the interconnected irrigation system that supplies the five surveyed dams. Dam codes: $A V O=$ Avoca: $D B=$ Dunbrody; $S L S=$ Surle Sun; OLI = Olifantsklip; $D C=$ Disco Chicks.

The aim of this study was to contribute to the knowledge base for this alien species by assessing the population structure and relative abundance of G. affinis in an irrigation network in the Sundays River catchment in the Eastern Cape of South Africa. In particular, we sought to characterise the seasonal shifts in population size and growth rates, and to assess the potential role of physical (habitat) and biotic drivers (interactions with other fish species) on these dynamics. We therefore investigated population dynamics of G. affinis within the irrigation dams over the course of a single breeding season, beginning in summer and ending in winter.

\section{METHODS}

\section{Study area}

Sampling was conducted in the Sundays River Valley in the Eastern Cape Province of South Africa. This agricultural area produces mainly citrus and utilises an extensive interconnected network of canals as an irrigation source. The canal network originates from the Korhaansdrift weir, east of Kirkwood, and branches out $54 \mathrm{~km}$ down the valley. The canals supply approximately 400 dams used as reservoirs to irrigate citrus orchards. Sampling was conducted in 5 dams situated among the citrus farms of the Sundays River Valley (Fig. 1). These dams were selected because pilot surveys had identified established G. affinis populations. Two of the dams represented new aquatic habitats, being 1 and 2 years old, whilst the remaining three dams were between 10 and 33 years old, representing old and well established aquatic habitats. The dams, named for the respective farms on which they were built, were Avoca (AVO), Dunbrody (DB), Sur le Sun (SLS), Olifantsklip (OLI) and Disco Chicks (DC).

\section{Fish sampling}

Four monthly sampling trips were conducted in February, March, April and June (2012). February to April represented mid- to late-summer and June represented early winter. Gambusia affinis are known to congregate in the shallow littoral zone of still-water bodies (Miura et al., 1979), and are generally associated with submerged aquatic vegetation (Casterlin and Reynolds, 1977). Thus, within each of the 5 dams, 4 randomly-selected sampling sites along the water's edge were surveyed in order to capture variability in vegetation cover. Each site was resampled in subsequent sampling trips. Sampling was conducted using a scoop net with a mesh size of $2 \mathrm{~mm}$ and a hoop diameter of $75 \mathrm{~cm}$. Four sweeps were conducted in each site, with each sweep covering an area of $4 \mathrm{~m}^{2}$ with a maximum depth of $75 \mathrm{~cm}$. The net was scooped with a quick and thorough action through the vegetation along the banks of the dam. After each sweep, all fish captured were identified and each species present in the net was counted and recorded. All G. affinis were anaesthetised with clove oil and retained for biological analysis. Other species, which included the non-native Mozambique tilapia (Oreochromis mossambicus) and native river goby (Glossogobius callidus), were returned to the water.

\section{Physico-chemical parameters}

All dams received water from the same source (the irrigation network), thus water quality parameters were expected a priori to be similar among the dams. This assumption was tested during pilot surveys conducted in July 2011, where conductivity, $\mathrm{pH}$ and dissolved oxygen were assessed at all five dams using a YSI multi-probe sonde (Table 1). One-way ANOVA on physicochemical data revealed only $\mathrm{pH}$ to vary significantly among the sampled dams $(p<0.05)$. However, given the relatively narrow total range of recorded $\mathrm{pH}$ values (8.6-9.7) in the different impoundments, this variation was deemed not to be biologically meaningful. Later, during each sampling event, a temperature probe was used to record temperatures at 4 randomlyselected sampling sites in each dam. Water temperatures in the dams during the sampling period ranged between $25.6^{\circ} \mathrm{C}$ in February 2012 and $12.8^{\circ} \mathrm{C}$ in July 2012 (Table 1 ). The percentage of aquatic vegetation cover present in each sweep area was estimated and categorised into 4 percentage cover categories $(0 \%, 33.3 \%, 66.6 \%$ and $99.9 \%)$ which represented, respectively, no vegetation cover, low vegetation cover, medium vegetation cover and dense vegetation cover. Three dams (AVO, DB, OLI) had relatively high proportions of vegetation, while the remaining two (SLS, DC) had low vegetative cover (Table 1). Available vegetative cover did not change visibly over the sampling period. Total sweeping surface area per dam was calculated 
TABLE 1

Summary of physio-chemical charateristics for each dam in the Sundays River Valley. Conductivity, dissolved oxygen and pH were recorded during pilot surveys in June 2011. Temperature and percentage vegetative cover were monitored during the sampling period between February and June 2012. Dam codes: DC = Disco Chicks; OLI = Olifantsklip; SLS = Sur le Sun; AVO =

\begin{tabular}{|c|c|c|c|c|c|c|c|}
\hline \multicolumn{8}{|c|}{ Avoca; DB = Dunbrody. } \\
\hline Dam & $\begin{array}{l}\text { Conductivity } \\
\left(\min ; \max ^{-1}\right) \\
\left(\mathrm{mS} \cdot \mathrm{m}^{-1}\right)\end{array}$ & $\begin{array}{c}\text { Dissolved } \mathrm{O}_{2} \\
\underset{(\mathrm{min} ; \mathrm{max})}{\left(\mathrm{mg} \cdot \ell^{-1}\right)}\end{array}$ & $\begin{array}{c}\mathrm{pH} \\
(\min ; \max )\end{array}$ & $\begin{array}{c}\text { Temperature } \\
(\min ; \max )\left({ }^{\circ} \mathrm{C}\right)\end{array}$ & $\begin{array}{l}\text { Circumference } \\
\text { (m) }\end{array}$ & $\begin{array}{c}\text { Mean \% } \\
\text { veg cover }\end{array}$ & $\begin{array}{c}\text { Age } \\
\text { (years) }\end{array}$ \\
\hline DC & $9.4 ; 9.9$ & $8.9 ; 9.3$ & $8.9 ; 9.3$ & $14.0 ; 25.6$ & 462 & 14.4 & 1 \\
\hline OLI & $4.5 ; 4.6$ & $10.6 ; 10.7$ & $9.4 ; 9.7$ & $14.2 ; 25.1$ & 278 & 75.0 & 2 \\
\hline SLS & $5.3 ; 5.3$ & $9.6 ; 10.4$ & $8.6 ; 9.7$ & $14.3 ; 25.2$ & 415 & 12.5 & 10 \\
\hline AVO & $9.9 ; 9.9$ & $9.6 ; 10.3$ & $9.2 ; 9.3$ & $14.0 ; 24.0$ & 260 & 64.8 & 19 \\
\hline DB & $5.9 ; 5.9$ & $10.2 ; 10.5$ & $8.9 ; 9.7$ & $12.8 ; 24.7$ & 395 & 75.0 & 33 \\
\hline
\end{tabular}

using dam circumference and was measured using Google Earth's measurement application and satellite images.

\section{Statistical analysis}

Recorded counts of each species captured per sweep were used to investigate the difference in species relative abundance between dams and sampling events over the sampling period. The relative abundance of each of species was measured as Catch per Unit Effort (CPUE), which represents the number of fish caught per scoop.

A repeated-measures ANOVA was used to test the differences in G. affinis CPUE between dams and over sequential sampling events, to assess whether or not a 'boom-bust' pattern of rapid population growth and subsequent decline occurred in each of the five sampled populations. CPUE of G. affinis were square-root transformed to meet ANOVA assumptions of normality and homoscedasticity. Significant differences in CPUE between individual sampling events were then examined using post hoc Tukey tests. The analyses were conducted using the statistical package, Statistica 10.

The average rate of increase of G. affinis per scoop per day was used to further compare the relative population growth patterns between dams across the sampling months. The average rate of increase of G. affinis per scoop per day (within each dam) was calculated using the difference in CPUE between adjacent sampling events (for each dam) and dividing that figure by the number of days that had occurred between the two sampling events. The average rate of increase of G. affinis per scoop per day was determined between all sampling events and individually calculated for each of the five dams. By graphically assessing the relative growth pattern expressed by each dam, the timing of key inflection points in the population dynamics of the five populations was then assessed.

To assess the relative importance of abiotic and biotic factors in controlling G. affinis population size, a general linear model (GLM) was used to test the effects of dam age, temperature, O. mossambicus CPUE, G. callidus CPUE and proportional density of vegetation on the relative abundance (CPUE) of G. affinis. These factors represented biologically important potential drivers of G. affinis population dynamics, which variance inflation analysis within the GLM showed to be orthogonal. CPUE of all three fish species were squareroot transformed to meet GLM assumptions of normality and homoscedasticity. Similarly, continuous abiotic factors were natural-log transformed, while proportional vegetation density was arcsin-square-root transformed. All statistical analyses were performed in Statistica 10.

\section{RESULTS}

A total of 8096 fish were captured during the study. Of these, 6669 were G. affinis, 1242 were O. mossambicus and 185 were G. callidus. Gambusia affinis were captured in $87 \%$ of sweep samples, indicating CPUE estimates were not biased by high numbers of zero catches. The repeated measures ANOVA showed G. affinis populations to vary significantly among dams and across sampling events, with a significant interaction between sampling locality and sampling event also evident (Table 2). This result shows that, while G. affinis population size rose and fell significantly in all five dams over the season, the magnitude of both population increases and decreases varied from dam to dam (Fig. 2). For example, while the dams AVO (Fig. 2a), SLS (Fig. 2c) and OLI (Fig. 2d) all showed significant population declines in the fourth and final (winter) sampling event, no such trend was evident in the remaining two dams. Dam DB in contrast showed a significant increase in CPUE over the first three sampling events, without a significant crash in winter (Fig. 2b), while DC showed no significant variation in CPUE across the study period (Fig. 2e). Despite these variations in population dynamics, an overall trend of rapid increase, plateau, and then severe decline in density in the final winter sample was evident across all dams when the effect of sampling event alone was plotted (Fig. 2f).

In all dams, G. affinis demonstrated a positive population growth rate during the first 36 days of the study (Fig. 3; Table 3) with a mean relative population increase rate of a rapid 0.376 fish.scoop ${ }^{-1} \cdot$ day $^{-1}$. Between Days 0 and 36 , the greatest relative population increase occurred in Dam DC, 0.444 fish.scoop ${ }^{-1}$.day ${ }^{-1}$, and the lowest in Dam SLS (0.283 fish. $\operatorname{scoop}^{-1} \cdot$ day $\left.^{-1}\right)$. Thereafter, as the mean water temperature dropped from $24.1^{\circ} \mathrm{C}$ to $18.0^{\circ} \mathrm{C}$ between Days 36 and 85 , G. affinis population growth rates in all dams declined steadily to 0.113 fish.scoop ${ }^{-1} \cdot$ day $^{-1}$. The G. affinis population in SLS was the first to demonstrate a negative rate of population growth of $-0.128 \mathrm{fish} \cdot \mathrm{scoop}^{-1} \cdot \mathrm{day}^{-1}$, and also exhibited the greatest

\section{TABLE 2}

Results of the repeated measures ANOVA assessing the effects of sampling locality (dam), sampling event, as well as the interaction between these factors on square-root transformed G. affinis CPUE.

\begin{tabular}{|l|c|c|c|}
\hline Effect & $\mathrm{df}$ & $\mathrm{F}$ & $\mathrm{p}$ \\
\hline Dam & 4,71 & 5.23 & $<0.001$ \\
\hline Sample event & 3,213 & 39.54 & $<0.000001$ \\
\hline Dam x sample event & 12,213 & 4.73 & $<0.00001$ \\
\hline
\end{tabular}




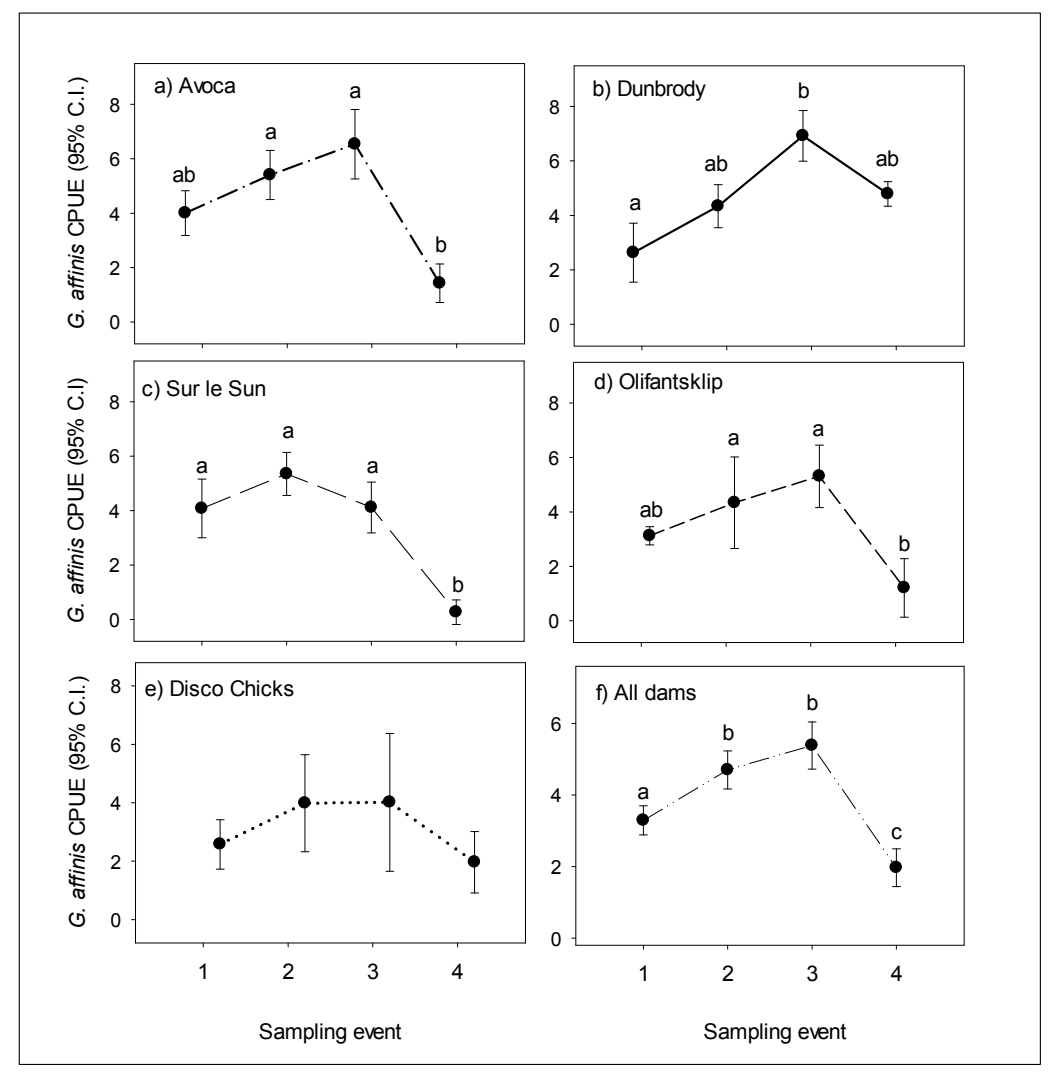

Figure 2

Mean ( $\pm 95 \%$ C. I.) squareroot transformed CPUE of Gambusia affinis in 5 dams visited 4 times in the summer, autumn and winter of 2012. Differing letters represent significant differences among sampling events $(p<0.05)$ as detected by post-hoc Tukey tests on the repeated measures ANOVA. Sampling events are: $1=$ February; $2=$ March $3=$ April 2012 4 = June 2012

TABLE 3

Mean rate increase of G. affinis per scoop per day recorded during the summer months and winter month. Dam codes: DC = Disco Chicks; OLI = Olifantsklip; SLS = Sur le Sun; AVO = Avoca; DB = Dunbrody.

\begin{tabular}{|c|l|c|c|c|c|}
\hline & Month & February & March & April & June \\
\hline \multirow{5}{*}{$\begin{array}{l}\text { Mean tempe- } \\
\text { rature }\left({ }^{\circ} \mathrm{C}\right)\end{array}$} & 24.9 & 24.1 & 18.0 & 13.9 \\
\hline \multirow{5}{*}{ Dam } & $\begin{array}{l}\text { Day of sam- } \\
\text { pling event }\end{array}$ & 0 & 36 & 85 & 156 \\
\hline \multirow{5}{*}{} & DC & 0 & 0.444 & 0.112 & -0.173 \\
\cline { 2 - 6 } & OLI & 0 & 0.424 & 0.070 & -0.174 \\
\cline { 2 - 6 } & SLS & 0 & 0.283 & -0.128 & -0.122 \\
\cline { 2 - 6 } & AVO & 0 & 0.378 & 0.191 & -0.285 \\
\cline { 2 - 6 } & DB & 0 & 0.351 & 0.321 & -0.146 \\
\hline & Mean & 0 & 0.376 & 0.113 & -0.900 \\
\hline
\end{tabular}

\section{TABLE 4}

General linear model effects of dam age (years), temperature $\left({ }^{\circ} \mathrm{C}\right)$, O. mossambicus CPUE, G. callidus CPUE and relative density of vegetation on the CPUE of G. affinis from February 2012 to June 2012. Parameter estimates with $95 \%$ confidence intervals are shown for factors with significant $(p<0.05)$ effects.

\begin{tabular}{|l|c|c|c|c|c|}
\hline Effect & df & $\mathbf{F}$ & $\mathbf{p}$ & $\begin{array}{c}\text { Parameter } \\
\text { estimate }\end{array}$ & $\begin{array}{c}95 \% \text { Conf. } \\
\text { Interval }(-;+)\end{array}$ \\
\hline Dam age (years) & 1 & 3.852 & 0.051 & - & - \\
\hline Temperature $\left({ }^{\circ} \mathrm{C}\right)$ & 1 & 11.595 & 0.001 & 2.441 & $(1.03 ; 3.85)$ \\
\hline O. mossambicus CPUE & 1 & 1.078 & 0.300 & - & - \\
\hline G. callidus CPUE & 1 & 7.301 & 0.007 & -0.569 & $(-0.98 ;-0.15)$ \\
\hline Vegetative cover & 1 & 0.516 & 0.473 & - & - \\
\hline Error & 298 & - & - & - & - \\
\hline
\end{tabular}

decline in population growth rate, of 0.411 fish $\cdot \mathrm{scoop}^{-1} \cdot \mathrm{day}^{-1}$. Of the remaining populations, OLI demonstrated the most rapid decline in population growth rate and DB the slowest, between Days 36 and 85 (Fig. 3). Subsequently, after Day 85, when temperatures dropped from $18^{\circ} \mathrm{C}$ to $13.9^{\circ} \mathrm{C}$, populations in all dams expressed negative population growth rates indicating significant declines in population size (Fig. 3, Table 3).

Results from the GLM assessing drivers of G. affinis population size revealed that dam age (years), vegetation cover (\%) and the CPUE of O. mossambicus had no effect on the CPUE of G. affinis (Table 4). However, water temperature had a significant positive effect on G. affinis CPUE, while the CPUE of $G$. callidus had a significant negative effect (Table 4).

\section{DISCUSSION}

Previous international research has shown Gambusia affinis populations to increase over the summer months, and there have been reports that they are able to produce multiple generations within a single breeding season, before declining in numbers during the winter (Pyke, 2005). This study provides new insight into the timing and variation of these population dynamics in colonised freshwater habitats in South Africa, where the biology of this invasive species is poorly known. The population growth pattern exhibited by G. affinis in the Sundays River Valley elucidates the previously described boom and bust trend that occurs in conjunction with the summer and winter season (Pyke, 2005). This boom and bust pattern is clearly illustrated both by the seasonal variation in CPUE, as well as the variation detected in population growth rates over time. 


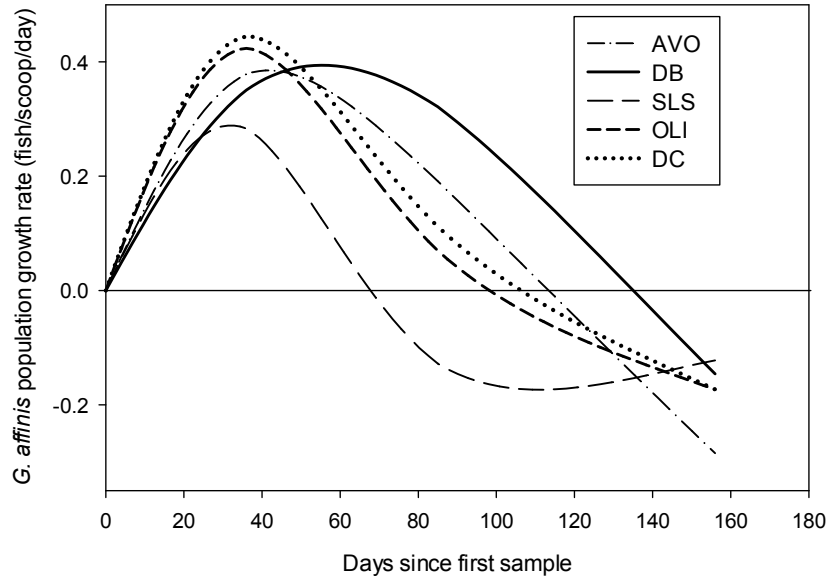

Figure 3

Average rate of increase of $G$. affinis per scoop per day recorded in each dam over the duration of the study, illustrated by interpolated splines based on 4 calculations of population growth rate (at Days $0,36,85$ and 156; Table 3). Dam codes: $A V O=$ Avoca; DB = Dunbrody; SLS = Sur le Sun; $O L I=$ Olifantsklip; $D C=$ Disco Chicks

Sample locality, sampling event and the interaction between sampling events and dams sampled had a significant effect on the relative abundance of $G$. affinis ( $p<0.05$ in all cases). Repeated measures ANOVA revealed an overall significant difference only between Dams DB and DC, where the combined CPUE data in DB was significantly higher than for DC. Despite this significant effect of sampling locality, there was no clear evidence that the actual location of the dams affected G. affinis populations in a meaningful way. The five populations were thus considered comparable for the purposes of this study.

The assessment of G. affinis CPUE across sampling events for all dams revealed significant overall differences between early summer (February), late summer (March and April) and winter (June), corresponding to a boom, plateau and subsequent bust across the majority of G. affinis populations. These trends represent a rapid increase in the relative population growth rate of G. affinis observed between the summer months of February and March, and take place when breeding and birth rates were likely to be at their height (Pyke, 2005). Thereafter, as the water temperature declined between March and April, the fish appear to have stopped breeding and population growth rates in all of the dams gradually began to decline in congruency with the dropping temperature.

The GLM assessing potential biotic and abiotic drivers of G. affinis CPUE showed water temperature to have a significant effect on G. affinis during the course of the summer and winter. This phenomenon reflects the normal life history pattern that G. affinis has adapted to, whereby breeding and the production of clutches of juveniles peak in the warm summer months (Pyke, 2005). The strong link between temperature and population dynamics suggest it is the primary controlling factor, which may supersede the influence of other abiotic and biotic factors on the species, particularly during winter.

One such factor thought a priori to be an important driver of local abundance of $G$. affinis was the percentage of submerged vegetative cover, given the species' well known association with such habitat features (Casterlin and Reynolds, 1977). However, in this study vegetative cover had no significant effect on G. affinis CPUE, which suggests that the invasive success of G. affinis in South African impoundments may be independent of the presence of aquatic foliage or similar habitat.
Interestingly, the dams containing the largest and smallest G. affinis populations across all sampling events (DB and DC, respectively) also differed significantly in vegetative cover (with DB containing denser marginal vegetation). This association was however not consistently observed among the other dams, and is thus difficult to interpret.

Gambusia affinis densities were not influenced by the relative abundance of $O$. mossambicus, although the two species shared the same microhabitats along the edge of the dams. A likely explanation for the lack of interspecific interactions may be in the different feeding habits of G. affinis and O. mossambicus. Gambusia affinis is a pelagic and surface predatory fish (Pyke, 2005), while O. mossambicus swim throughout the entire water column and are more generalist, feeding on diatoms, algae and detritus as well as animal prey (Russell et al., 2012). They can therefore avoid competing for food resource by shifting their diet (Bowen and Allanson, 1982).

The GLM did, however, reveal that populations of G. affinis were negatively affected by the relative abundance of $G$. callidus populations within the sampled littoral habitats of the dams. Since G. callidus also feeds opportunistically on small invertebrates or any abundant prey (Skelton, 2001), there is likely to be interspecific competition between the two species. Glossogobius callidus may also represent a predatory threat to small G. affinis, which may precipitate avoidance behaviour in the latter species. Although not measurable using littoral zone surveys alone, spatial and seasonal variation in populations of G. callidus across the dams may have played a role in the variation in population size and growth rates observed between the five G. affinis populations. The potential ability of a native predator like G. callidus to regulate the local abundance of an invasive species like G. affinis is noteworthy, and merits further investigation.

In conclusion, the invasive success of G. affinis appears to be dependent on seasonal water temperature patterns and their interaction with the other predatory fish. Given that their optimal temperature preference is between 31 and $35^{\circ} \mathrm{C}$ (Pyke, 2005), it would seem that the impoundments of the Eastern Cape are towards the lower limit of their geographic range, a fact borne out by their severe winter mortality. Nonetheless, given the rapidity with which they establish viable populations within even these cold environments (in this case a dam only 1 year old), one cannot doubt the invasive nature of this species within South Africa.

\section{ACKNOWLEDGMENTS}

This study was jointly funded by a Water Research Commission research grant (WRC Project No. K5/2039) and a National Research Foundation post-doctoral fellowship (to DJW). DJW and OLFW also acknowledge support from the DST-NRF Centre of Excellence for Invasion Biology. We thank

K Docherty and M Hazell for assistance in the field. We thank Dr H Du Plessis and the water management staff of the Lower Sundays River Water Users Association for their support of the project, and for providing GIS databases on the irrigation scheme. We thank the many landowners of the Sundays River valley for land access, and SAIAB staff E Wolhuter and F Lamont for logistical support. Fieldwork was performed in accordance with SAIAB Animal Ethics guidelines. Permits to sample freshwater fishes in the Sundays River system were issued by the Eastern Cape Department of Economic Development and Environmental Affairs (DEDEA) and South African National Parks. 


\section{REFERENCES}

BOWEN SH and ALLANSON BR (1982) Behavioral and trophic plasticity of juvenile Tilapia mossambica in utilization of the unstable littoral habitat. Environ. Biol. Fishes 7 357-362.

CASTERLIN ME and REYNOLDS WW (1977) Aspects of habitat selection in the mosquitofish Gambusia affinis. Hydrobiologia. 55 125-127.

DE MOOR IJ and BRUTON MN (1988) Atlas of the alien and translocated indigenous aquatic animals in southern Africa. South African National Scientific Programmes, Report 144. Foundation for Research Development/CSIR, Pretoria.

JOHNSON PT, OLDEN JD and VANDER ZANDEN MJ (2008) Dam invaders: impoundments facilitate biological invasions into freshwaters. Front. Ecol. Environ. 6 357-363.

LEPRIEUR F, BEAUCHARD O, BLANCHET S, OBERDORFF T and BROSSE S (2008) Fish invasions in the world's river systems: When natural processes are blurred by human activities. PLoS Biol. 6 (2) e28. DOI:10.1371/journal.pbio.00600280404.

LOWE S, BROWNE M, BOUDJELAS S and DE POORTER M (2000) 100 of the World's Worst Invasive Alien Species: A Selection from the Global Invasive Species Database. The Invasive Species Specialist Group (ISSG) a specialist group of the Species Survival Commission (SSC) of the World Conservation Union (IUCN). 12 pp. First published as special lift-out in Aliens 12, December 2000

MACK RN, SIMBERLOFF D, LONSDALE WM, EVANS H, CLOUT $M$ and BAZZAZ FA (2000) Biotic invasions: causes, epidemiology, global consequences, and control. Ecol. Appl. 10 689-710.

MIURA T, TAKASHI RM and STEWART RJ (1979) Habitat and food selection by mosquitofish Gambusia affinis. Proc. Pap. Annu. Conf. Calif. Mosq. Vector Control Assoc. 47 46-50.
PYKE GH (2005) A review of the biology of Gambusia affinis and G.holbrooki. Rev. Fish Biol. Fish. 15 339-365.

PYKE GH (2008) Plague minnow or mosquito fish? A review of the biology and impacts of introduced Gambusia species. Annu. Rev. Ecol. Evol. Syst. 39 171-191.

PYKE GH and WHITE AW (2000) Factors influencing predation on eggs and tadpoles of the endangered Green and Gold Bell Frog (Litoria aurea) by the introduced Plague Minnow (Gambusia holbrooki). Austr. Zool. 31 496-505.

RAUCHENBERGER M (1989) Systematics and biogeography of the genus Gambusia (Cyprinodontiformes: Poecilidae). Am. Mus. Novit. 2951. 74 pp.

VAN RENSBURG BJ, WEYL OLF, DAVIES SJ, VAN WILGEN LJ, PEACOCK DS, SPEAR D and CHIMIMBA CT (2011) Chapter 15: Invasive Vertebrates of South Africa. In: Pimentel D (ed.) Biological Invasions: Economic and Environmental Costs of Alien Plant, Animal, and Microbe Species. ( $2^{\text {nd }}$ edn.) CRC Press, Boca Raton. 326-378.

RICHARDSON DM, WILSON JRU, WEYL O and GRIFFITHS CL (2010) South Africa: Invasions. In: Simberloff D and Rejmanek M (eds.) Encyclopedia of Biological Invasions. University of California Press, Berkeley. 643-651.

RUSSELL DJ, THUESEN PA and THOMSON FE (2012) A review of the biology, ecology, distribution and control of Mozambique tilapia, Oreochromis mossambicus (Peters 1852) (Pisces: Cichlidae) with particular emphasis on invasive Australian populations. Rev. Fish Biol. Fish. 22 533-554.

SKELTON P (2001) A Complete Guide to the Freshwater Fishes of Southern Africa. Struik Publishers, Cape Town. 278-279. 